\title{
Expansão de cursos/vagas de Graduação em Enfermagem e a qualidade do processo de formação da(o) enfermeira(o)
}

\author{
Josicelia Dumêt Fernandes' \\ ' Universidade Federal da Bahia, Escola de Enfermagem, Grupo de Estudos e Pesquisas em Educação, \\ Ética e Exercício de Enfermagem. Salvador-BA, Brasil. Revista Brasileira de Enfermagem, \\ Editora Associada, Gestão 2010-2013. Brasília-DF, Brasil.
}

As políticas públicas de educação têm evidenciado uma expressiva expansão da educação superior, por meio do aumento do número de instituições de ensino e, consequentemente, de cursos e vagas por elas ofertados. Esse entendimento expressa-se na Lei de Diretrizes e Bases da Educação Nacional (LDB) que, em 1996, viabilizou a ampliação quantitativa de Instituições de Ensino Superior, pela estratégia da interiorização e de aumento de cursos/vagas nas grandes metrópoles. Por outro lado, o Plano Nacional de Educação apresentou uma política de Estado para o decênio 2001-2010, estabelecendo, entre outras metas, uma ampliação da oferta de vagas em cursos superiores, compatível com 30\% dos jovens entre 18 e 24 anos. Dentre os dispositivos legais posteriores à LDB, merece destaque o Decreto $n^{\circ} 2.306 / 97$, que definiu a necessidade da indissociabilidade entre ensino, pesquisa e extensão, apenas para as universidades. As demais instituições de ensino não necessitariam dedicar-se à pesquisa, o que evidenciou uma formação deslocada do eixo da indissociabilidade do ensino com a pesquisa e com a extensão, restringindo a educação superior à função de ensino, sem o foco da qualidade.

Ao tempo em que se possibilitou a ampliação quantitativa de instituições de ensino e de aumento do número de cursos/vagas, se favoreceu a formação de profissionais sem o suporte da pesquisa e da extensão e, consequentemente, sem o estímulo à criação do pensamento novo, à construção de novos conhecimentos, além da proliferação de cursos e instituições, muitos deles distantes da ideia de universidade e de padrões mínimos de qualidade.

Vale destacar que, segundo dados do INEP/MEC, em 2004, a área da Enfermagem contava com 415 escolas/cursos. Esse quantitativo passou para 838, em 2012, sendo 80,19\% na rede privada e 46,30\% na região sudeste. Isso evidencia que a expansão se deu, prioritariamente, na rede privada e na região sudeste. Ademais, vale registrar que essa expansão vem se dando de forma desarticulada com os cenários das práticas em saúde, ou seja, com os espaços de aprendizagem que envolvem a produção do cuidado, particularmente no que se refere às dificuldades de oportunidades de procedimentos práticos devido ao número excessivo de alunos nesses espaços de aprendizagem que não parecem ter tido sua expansão na mesma proporção que as instituições/cursos/vagas, ocasionando um desequilíbrio entre os espaços para o desenvolvimento das práticas em saúde/enfermagem e o quantitativo de alunos nesses espaços.

A política de expansão de cursos/vagas na área da saúde/enfermagem, desarticulada dos cenários das práticas, pode ter implicações danosas na efetivação de um processo de aprendizagem eficaz e de qualidade, limitando as oportunidades para a formação voltada para as dimensões do cuidado em saúde e para as relações dos profissionais com seus clientes, na construção de uma atenção integral no âmbito das unidades de saúde.

Faz-se importante pontuar que a necessidade de novos profissionais enfermeiros é uma realidade. Entretanto, ao tempo em que é necessário ampliar o número de enfermeiros no país, é necessário, também, que esses profissionais sejam formados num processo de qualidade voltado para atender às múltiplas e crescentes demandas sociais e sanitárias. Não basta reconhecer a importância da ampliação de número de enfermeiras(os) para o mercado, se esses profissionais não forem formados num padrão que preencha os requisitos necessários ao atendimento de qualidade à saúde da população. Não basta crescer a qualquer custo, é importante crescer desde que seja garantido o critério de qualidade e pertinência da formação. É 
necessário expandir, mas com garantia de padrões de qualidade compatíveis com o mundo contemporâneo e com vinculação mais estreita entre o mundo do trabalho e o mundo da formação.

Frente a essa realidade, a Associação Brasileira de Enfermagem (ABEn), como vem fazendo desde a sua criação, lidera uma luta em favor da qualidade da formação dos profissionais da Enfermagem, envolvendo parcerias, alianças, discussão em inúmeros fóruns, comissões e eventos, tais como o SENADEn, espaços para discussão e encaminhamento de proposições para o desenvolvimento da Educação em Enfermagem. Nesse sentido, destaca-se a construção do "Movimento em defesa da qualidade da formação dos profissionais da Enfermagem", iniciado em 2010.

Aos sujeitos do processo de formação (docentes, discentes, enfermeiros e gestores de instituições de ensino e saúde) cabe a necessidade de se engajarem nesse movimento, fortalecendo a luta por uma formação de qualidade, pautada nas Diretrizes Curriculares, nos princípios do SUS e nas necessidades sociais/saúde da população. 